\title{
SYNTHESIS OF BIS $(\beta$-DIKETONATO)ZIRCONIUM (IV) CHLORIDE AS A CATALYST IN THE RING OPENING POLYMERIZATIONS OF $\varepsilon$-CAPROLACTONE
}

\author{
M. Yusuf ${ }^{1, *}$, D. Roza $^{1}$, Nurfajriani ${ }^{1}$, H. Gunawan ${ }^{1}$ and N. Dari $^{1}$ \\ ${ }^{1}$ Department of Chemistry, Universitas Negeri Medan, Jl. Willem Iskandar, \\ Medan, 20221, Indonesia \\ *E-mail: yusuf.6423@gmail.com
}

\begin{abstract}
Poly( $\varepsilon$-caprolactone) (PCL) is $a$ biodegradable polymer that is very attractive because of its properties such as high crystallinity, high permeability, and non-toxic. In this research, two series of bis( $\beta$-diketonato)zirconium (IV) chloride have been synthesized to be performed as a catalyst in the ring-opening polymerization (ROP) of $\varepsilon^{-}$ caprolactone $(\varepsilon-\mathrm{CL})$. The polymerization reaction was performed at $100{ }^{\circ} \mathrm{C}$ by stirring the mixture in the oil bath for 4 hours. The results showed that the PCL has been successfully polymerized using bis( $\beta$-diketonato)zirconium (IV) chloride catalysts complex and its molecular structure has been determined by Fourier Transform Infrared (FTIR), Proton nuclear magnetic resonance ( $\left({ }^{1} \mathrm{HNMR}\right)$, Carbon Nuclear Magnetic Resonance $\left({ }^{13} \mathrm{CNMR}\right), \mathrm{X}$-ray Diffraction (XRD), Differential Scanning Calorimetry (DSC), and Thermogravimetric Analysis (TGA). On the other hand, the plausible reaction mechanism of the use of bis( $\beta$-diketonato)zirconium (IV) chloride catalyst in the ROP of $\varepsilon$-CL was also proposed in this research.

Keywords: $\operatorname{Bis}(\beta$-diketonato)zirconium(IV) Chloride, Ring Opening Polymerization, $\varepsilon$-Caprolactone, Poly $(\varepsilon$ caprolactone), Plausible Mechanism.

(c) Rasayan. All rights reserved
\end{abstract}

\section{INTRODUCTION}

Recent years, many researchers are interested in the synthesis of biodegradable polymers to reduce environmental pollution as a result of the inability of microorganisms to degrade petroleum base polymers. ${ }^{1-4}$ Unlike synthetic polymers, PCL is one of the biodegradable polymers that are easy to decompose. ${ }^{5-6} \mathrm{PCL}$ also has long term degradation so it's widely used for drug delivery systems and longterm implant devices. In addition, PCL has other interesting properties such as high crystallinity ${ }^{5}$, thermoplastic and mechanical properties that can be controlled ${ }^{5}$, biocompatibillity $^{5-6}$, permeability, and non-toxic materials. Hence, PCL has been adopted in various applications including packaging materials, implants, surgical sutures, vascular grafts, composite ${ }^{5}$, reinforcing agent $^{6}$, and bone screws. ${ }^{7-9}$

ROP of $\varepsilon$-CL is called living polymerization ${ }^{7}$ because as long as there is still a monomer, its reaction occurs continuously. Because of that, this polymerization has been widely interesting for many researchers for the last many years. They also have conducted ROP $\varepsilon$-CL by using modified Lewis acid complex as a catalyst and initiators. ${ }^{7-15}$ They have employed some of the catalysts and initiators such as nanoporous alumina membranes ${ }^{7}$, alkali metal salts ${ }^{8}$, bis-ligated magnesium complexes ${ }^{9}$, Ti Al-MCM$41^{10}$, tetrakis (acetylacetonato)zirconium ${ }^{11}$, metanesulfonic acid $^{12}$, aluminum complex ${ }^{13}$, zinc complex ${ }^{14}$, and distannoxane. ${ }^{15}$ But, some of their catalysts performed have some weaknesses. For example, they suffered from moisture and air. Then, they can also exposure to corrosive. In addition, they were difficult to control the Lewis acidity at the metal center.

Moreover, the ROP of $\varepsilon$-CL has been performed by using the tetrakis(acetyletonato)zirconium (IV) complex as a catalyst by another group research. Their catalysts have a similar $\beta$-diketonate ligand. But, they have a different coordination number $(\mathrm{CN}=4)$. PCL that they produced only resulted in a low degree of polymerization (DP) degree $(\mathrm{DP}=8) .{ }^{11}$ It is expected that, this research can produce PCL which has a

Rasayan J. Chem., 12(4), 2132-2140(2019)

http://dx.doi.org/10.31788/RJC.2019.1245463

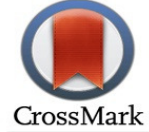


high degree of polymerization (DP>8) by using bis( $\beta$-diketonato)zirconium (IV) chloride catalysts. The PCL which high DP will produce good mechanical properties such as high crystalline, high decomposition temperature, and biocompatible..$^{5-9}$

In this research, ROP of $\varepsilon$-CL will have been performed by using two series of bis $(\beta$ diketonato)zirconium (IV) chloride complex catalyst $(\mathrm{CN}=2)$ as a modified Lewis acid catalyst. This complex is not corrosive, and also not moisture and air-sensitive based on the results of characterization (FT-IR, ${ }^{1} \mathrm{H}$ NMR, elemental analysis) and its reaction as depicted in scheme-1. ${ }^{16-17}$ Moreover, the zirconium complex is easy to control the Lewis acidity at the metal center by changing the withdrawing (phenyl) or donor electron character on the ligand (methyl).

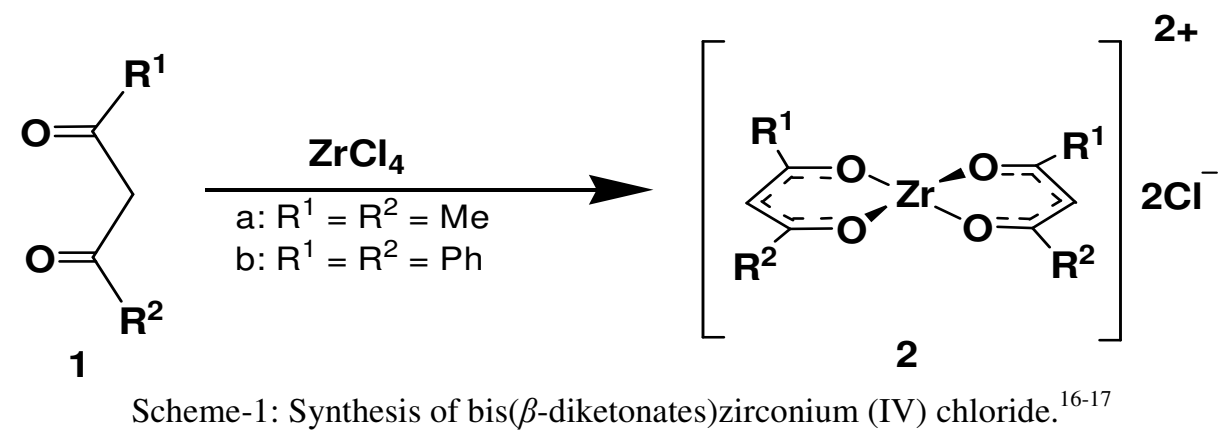

\section{Material and Methods}

\section{EXPERIMENTAL}

This research was carried out at the Inorganic Laboratory, Universitas Negeri Medan. Zirconium tetrachloride, $\beta$-diketonate ligands, and $\varepsilon$-CL were obtained from Merck. Perkin Elmer Life spectrometer displayed the IR spectra while KBR pellets were used for the solid form in samples. ${ }^{1} \mathrm{H}$ NMR and ${ }^{13} \mathrm{C}$ NMR $(500 \mathrm{MHz})$ spectra were recorded on Agilent 500 spectrometer in $\mathrm{CDCl}_{3}$. X-ray powder diffractions (XRD) were performed on an XRD-6100 Shimadzu diffractometer using $\mathrm{Cu}-\mathrm{K}_{\alpha}$ radiation. The melting temperature and enthalpy melting were analyzed by differential scanning calorimetry (DSC60 Plus Series: SHIMADZU) at $10{ }^{\circ} \mathrm{C} / \mathrm{min}$ which the heating is ranged between $40{ }^{\circ} \mathrm{C}$ and $550{ }^{\circ} \mathrm{C}$. The decomposition temperature was analyzed by thermogravimetry analysis (NETZSCH STA 449 F1 Jupiter) at $10{ }^{\circ} \mathrm{C} / \mathrm{min}$ which the heating is ranged between $40{ }^{\circ} \mathrm{C}$ and $550{ }^{\circ} \mathrm{C}$.

\section{Synthesis of Bis( $\beta$-diketonates)Zirconium (IV) Chloride}

A mixture of zirconium tetrachloride $(1 \mathrm{mmol})$, acetylacetone ligand (1a) $(2.4 \mathrm{mmol})$, and benzene solvent was stirred under an inert atmosphere at room temperature for 3 hours. After that, the mixture which had been reacted was refluxed for 14 hours. Furthermore, the resulting mixture was cooled and then left until the product precipitate forms whereas the filtrate are removed. Finally, the product was washed using n-hexane and dried in vacuo to produce bis(acetylacetone)zirconium (IV) chloride (2a). The same treatment was also done for the reaction using dibenzoylmethane (1b) ligand to produce bis(dibenzoylmethane)zirconium (IV) chloride (2b). ${ }^{16-17}$

\section{Ring-Opening Polymerization of $\varepsilon$-Caprolactone}

$\operatorname{Bis}(\beta$-diketonates)zirconium (IV) chloride $(0.21 \mathrm{mmol})$ catalyst was dissolved in $5 \mathrm{~mL}$ methanol and put into a schlenk flask. Then, methanol was evaporated by heating at $80{ }^{\circ} \mathrm{C}$ and drying in vacuo for 4 hours. Furthermore, $\varepsilon$-CL monomer $(44 \mathrm{mmol})$ and zirconium $\beta$-diketonate catalyst were mixed at room temperature in the schlenk flask.

Polymerizations were heated at $100{ }^{\circ} \mathrm{C}$ for $4 \mathrm{~h}$ in the oil bath. The product was then slowly dissolved using $30 \mathrm{~mL}$ chloroform and stirred using the sonication method for 30 minutes. After that, the product was stirred for 2 hours until dissolved and then refluxed to produce a clear solution. Next, that solution was precipitated using diethyl ether. Last, it is filtrated and dried in a vacuum pump to produce a white polymeric solid. The resulting PCL was measured by using FT-IR, ${ }^{1} \mathrm{H}$ NMR, XRD, TGA, and DSC. ${ }^{15}$ 


\section{Computational Method}

PM3 semi-empirical method was carried out to optimize the complex and reactant structure which is proved more accurate to calculate the geometries of zirconium complexes. Then, the geometry structure was calculated and visualized using the HyperChem 8.0 program package which runs by a personal computer with Windows 07 operating system. ${ }^{18-20}$ Furthermore, all energies were applied to the PolakRibiere minimization algorithm and were minimized to the RMS gradient of less than $0.1 \mathrm{kcal} /\left(\mathrm{A}^{\circ}\right.$ mol). ${ }^{11}$

\section{IR and ${ }^{1} H$ NMR Spectroscopies}

\section{RESULTS AND DISCUSSION}

The FT-IR spectra of two PCL obtained by using catalyst $2 a-2 b$ as founded by other research groups are shown in Figure-1. ${ }^{21}$ All FT-IR spectra showed $\mathrm{CH}_{2}$ - asymmetric absorption and $\mathrm{CH}_{2}$ - symmetrical absorption group at $2949 \mathrm{~cm}^{-1}$ and at $2865 \mathrm{~cm}^{-1}$. Then, the absorption band at $1470 \mathrm{~cm}^{-1}$ is related to asymmetric $\mathrm{CH}$ - from $\mathrm{CH}_{2}$ - scissoring. While the absorption band at $732 \mathrm{~cm}^{-1}$ is related to the rocking movements of methylene (CH-).

Furthermore, the characteristic absorption band at $1724 \mathrm{~cm}^{-1}$ is related to an ester group of PCL $(\mathrm{C}=\mathrm{O})$ while the absorption band at $1248 \mathrm{~cm}^{-1}$ is related to a strain of C-O ester. Based on these FTIR spectra, PCLs have been formed and the reaction is depicted in Scheme-2.

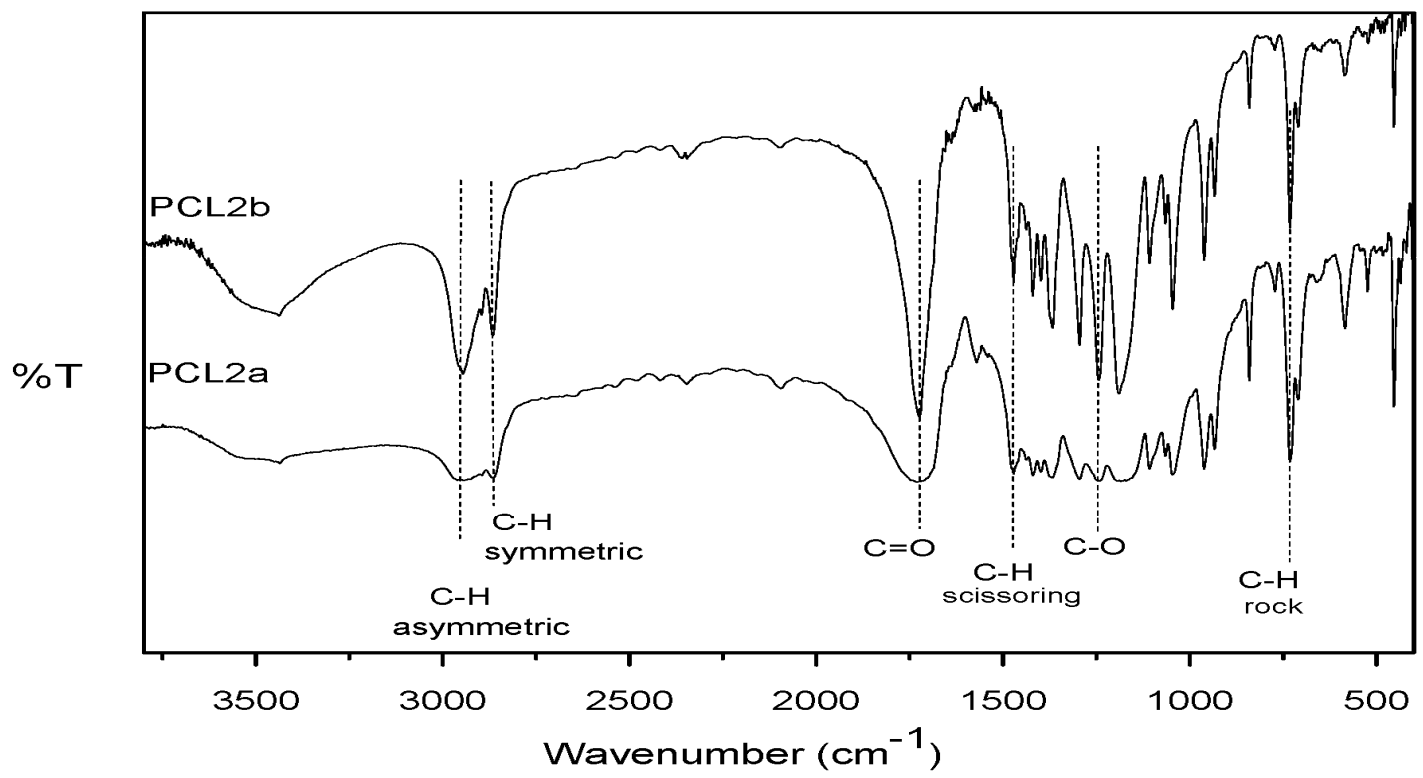

Fig-1: FTIR Spectra of PCL Generated by Catalyst 2a (PCL2a); PCL Generated by Catalyst 2b (PCL2b).<smiles>CC1CC(=O)[C]OC1=O</smiles><smiles>CC(C)(C)OCCCCCC(=O)C(C)(C)C</smiles>

Scheme-2: ROP of $\varepsilon$-CL using $2 \mathrm{a}-2 \mathrm{~b}$ Catalyst

${ }^{1} \mathrm{HNMR}$ spectra of PCL generated by catalyst $2 \mathrm{a}-2 \mathrm{~b}$ in $\mathrm{CDCl}_{3}$ solvent showed a similar ${ }^{1} \mathrm{HNMR}$ pattern as depicted in Fig.-2.

Based on the ${ }^{1} \mathrm{H}$ NMR analysis as reported in the previous research ${ }^{22-23}$, the chemical shifts in the range of $3.95-4.12 \mathrm{ppm}$ are related to $-\mathrm{CH}_{2}$ protons close to oxygen in ester bonds $\left(\mathrm{H}_{\mathrm{a}}\right)$. While the chemical shifts in the range of $2.23-2.37 \mathrm{ppm}$ is related to $-\mathrm{CH}_{2}$ protons close to the carbonyl group $\left(\mathrm{H}_{\mathrm{d}}\right)$. Last, the chemical shifts in the range $1.61-1.73 \mathrm{ppm}$ and around $1.30-1.47 \mathrm{ppm}$ is related to $-\mathrm{CH}_{2}$ protons in the 


\section{RASĀYAN J. Chem.}

Vol. 12 | No. 4 |2132 - 2140| October - December | 2019

polymer center $\left(\mathrm{H}_{\mathrm{b}}\right.$ and $\left.\mathrm{H}_{\mathrm{c}}\right)$. Based on this ${ }^{1} \mathrm{H}$ NMR result, $\varepsilon$-CL has been successfully polymerized in the existence of catalyst $2 \mathrm{a}-2 \mathrm{~b}$.

The degree of polymerization (DP) of PCL had also been calculated by using a comparison method between the integration ratio of naphthalene (proton signal $\mathrm{H}_{\mathrm{e}}$ and $\left.\mathrm{H}_{\mathrm{f}}\right)$ with PCL $\left(\mathrm{H}_{\mathrm{a}}, \mathrm{H}_{\mathrm{b}}, \mathrm{H}_{\mathrm{c}}, \mathrm{H}_{\mathrm{d}}\right.$ ) in the ${ }^{1} \mathrm{H}$ NMR spectrum. According to this calculation, it can be seen that the DP of PCL obtained using catalyst $2 \mathrm{~b}$ is 20 .
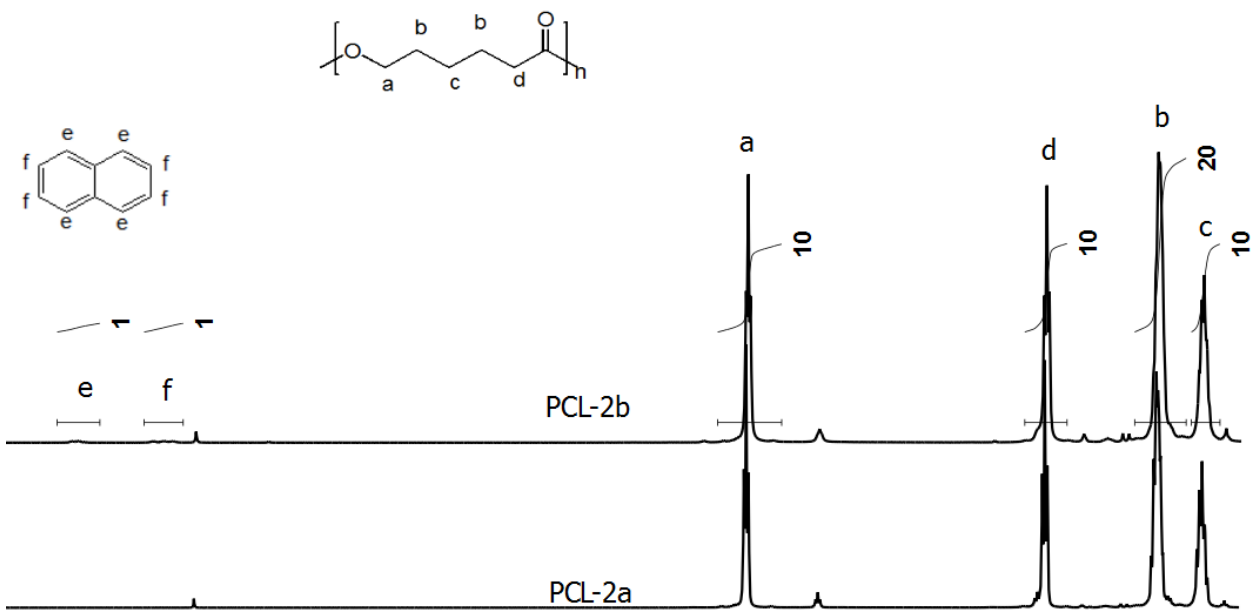

$\begin{array}{llllllllllllll}8.0 & 7.5 & 7.0 & 6.5 & 6.0 & 5.5 & \begin{array}{l}5.0 \\ 0(\mathrm{ppm})\end{array} & 4.5 & 4.0 & 3.5 & 3.0 & 2.5 & 2.0 & 1.5\end{array}$

Fig-2. ${ }^{1}$ HNMR Spectra of the PCLs Obtained Using Catalyst $2 \mathrm{a}-2 \mathrm{~b}$.
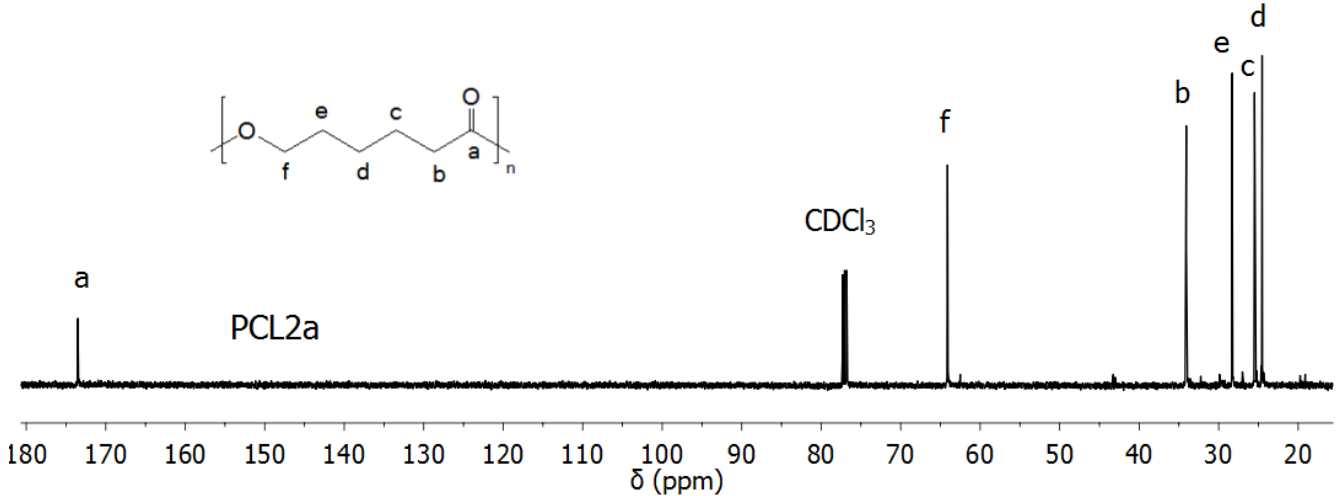

Fig-3: ${ }^{13}$ CNMR Spectra of the Obtained PCLs Using Catalyst 2a.

According to the ${ }^{13} \mathrm{C}$ NMR analysis, as shown in Fig.-3, it can be seen that the chemical shift at 173.5 ppm is related to the carbon that is in the carbonyl group $\left(-\mathrm{C}^{\mathrm{a}}\right)$, while the chemical shift in the range of $64.1 \mathrm{ppm}$ is related to $-\mathrm{CH}_{2}{ }^{\mathrm{f}}$ close to oxygen in the bond ester. Subsequently, chemical shifts at $34.06 \mathrm{ppm}$ are related to $-\mathrm{CH}_{2}{ }^{\mathrm{b}}$ close to the carbonyl group. Last, chemical shifts at $28.29 \mathrm{ppm}, 25.46 \mathrm{ppm}$, and around $24.55 \mathrm{ppm}$ are related to $-\mathrm{CH}_{2}{ }^{\mathrm{c}, \mathrm{d}, \mathrm{e}}$ at the polymer center. This result is in the almost similar chemical shifts range as explained by previous work. ${ }^{21}$ Based on this ${ }^{13} \mathrm{C}$ NMR result, $\varepsilon$-CL has been successfully polymerized in the existence of catalyst $2 \mathrm{a}$.

\section{X-Ray Diffraction (XRD) Analysis}

The characterization of the crystal and amorphous structure of PCL was conducted by using XRD analysis. XRD analysis can also be done to determine the crystal size and the level of PCL crystallinity. Crystalline polymers will produce sharp peaks, while amorphous polymers will produce wide peaks. In 
RASĀYAN J. Chem.

Vol. 12 | No. 4 |2132 - 2140| October - December | 2019

general, polymers consist of crystalline and amorphous phases so that most of the polymers tend to be semicrystalline.

The XRD pattern of PCL obtained using catalyst $2 \mathrm{a}-2 \mathrm{~b}$ as reported in the previous research which is shown in Fig.- $4 .^{24}$ The PCL crystal peak is overlapping at a wide peak $(2 \theta)$ from $15^{\circ}$ to $50^{\circ}$ which indicates an amorphous and crystalline contribution to PCL. Meanwhile, the sharp crystalline peak is located at around $2 \theta=21^{\circ} ; 22^{\circ}$; and $23^{\circ}$ in corresponding with reflection planes (110), (111) and (200). ${ }^{24}$ Based on the degree of crystallinity (Xc) calculation as depicted in Table 1, the Xc of PCL obtained using catalyst $2 a-2 b$ is in the range of $80-83 \% .^{24}$ These results indicate that the PCL obtained using $2 a-2 b$ catalyst is semicrystalline polymer so that the polymer reset unit in its chain is well organized. Meanwhile, the structure of the PCL is orthorhombic.

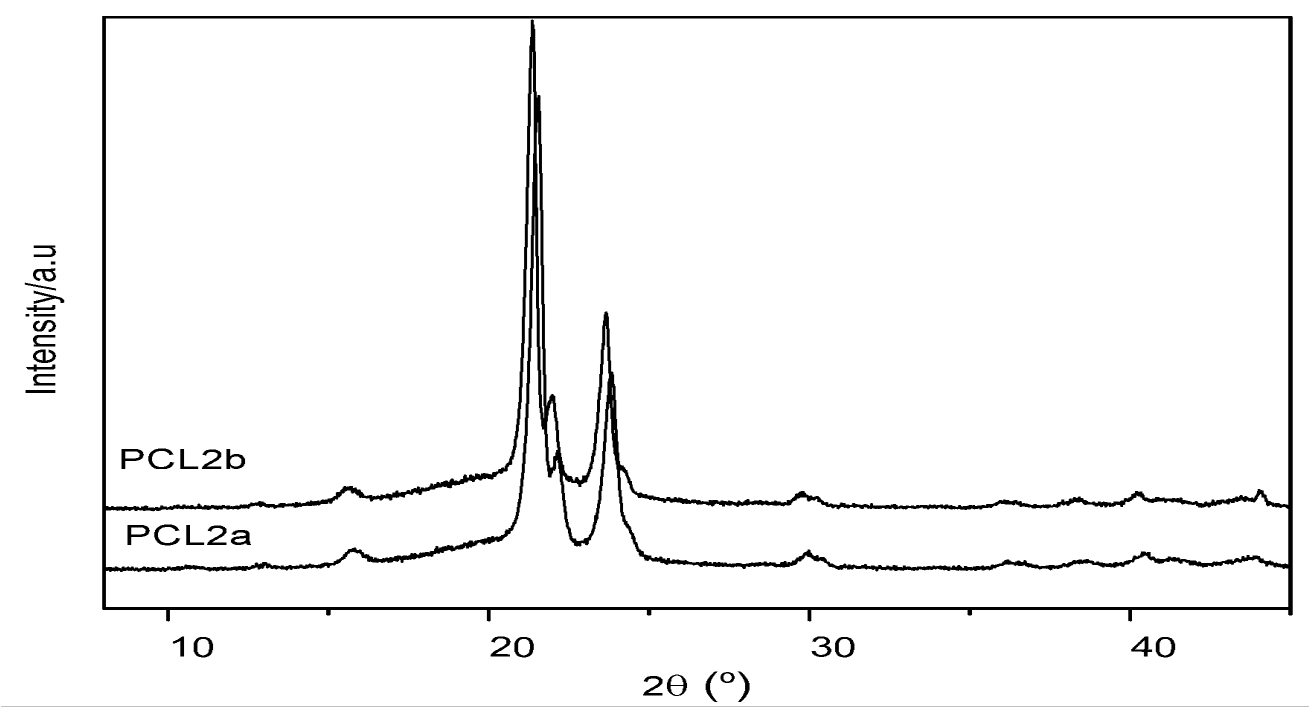

Fig.-4: XRD Pattern of PCL Obtained Using Catalyst 2a-2b (PCL 2a-PCL 2b)

The Scherrer equation as shown below (equation-1) is used to determine the crystallite size (D) of the PCL crystal. It is derived from calculating the amount of FWHM (Full Width at Half Maximum) from the peak of the XRD field. Whereas, the Origin software is used to make the Bragg angle.

$$
D=\frac{k \lambda}{F W H M \cos \theta}
$$

The meanings are, the value of Scherrer constant $(k)=0.94$, the value of X-ray wavelength $(\lambda)=0.15406$. FWHM is the crystal grain size, $\theta$ is the diffraction angle. ${ }^{25}$ The results of calculating the crystalline size of PCL are presented in Table-1.

Table-1. Crystallite Size (nm) for PCL (110), (111), and (200) Orientation Planes

\begin{tabular}{|c|c|c|c|c|c|}
\hline \multirow{2}{*}{$\begin{array}{l}\text { Crystallite } \\
\text { size }\end{array}$} & \multirow[b]{2}{*}{$2 \theta$} & \multicolumn{2}{|c|}{ PCL-2a } & \multicolumn{2}{|c|}{ PCL-2b } \\
\hline & & $\mathrm{nm}$ & $\mathrm{Xc}(\%)$ & $\mathrm{nm}$ & Xc (\%) \\
\hline D110 & 21 & 20.03 & \multirow{3}{*}{83} & 22.65 & \multirow{3}{*}{80} \\
\hline D 111 & 22 & 16.89 & & 16.43 & \\
\hline D 200 & 23 & 16.56 & & 19.38 & \\
\hline
\end{tabular}

$\mathrm{Xc}=\overline{\text { [the area inside the crystalline peaks / the total area inside all the peaks }] \mathrm{x}} 100 \%$

According to the results from calculating, the crystal size in the orientation plane 110 (D110), it was found that the D110 of PCL obtained using $2 \mathrm{a}-2 \mathrm{~b}$ catalysts were in the range 20.03-22.65 nm. Whereas, the crystal size of PCL obtained using $2 \mathrm{a}-2 \mathrm{~b}$ catalysts in the orientation plane 111 (D111) were in the range 16.43-16.89 $\mathrm{nm}$. Furthermore, the crystal size of PCL obtained using $2 \mathrm{a}-2 \mathrm{~b}$ catalysts in the 
orientation plane 200 (D200) were in the range 16.56-19.38 nm. These results show that the grains of nanocrystalline embedded in the amorphous matrix.

\section{Thermal Analysis}

The thermal properties of PCL analyzed using DSC as shown in Fig.-5. In particular, the DSC was used to investigate the melting temperature $(\mathrm{Tm})$ and melting enthalpy $(\Delta \mathrm{Hm})$ of PCL. The melting enthalpy $(\Delta \mathrm{Hm})$ shows some energy needed to reform the solid to the liquid.

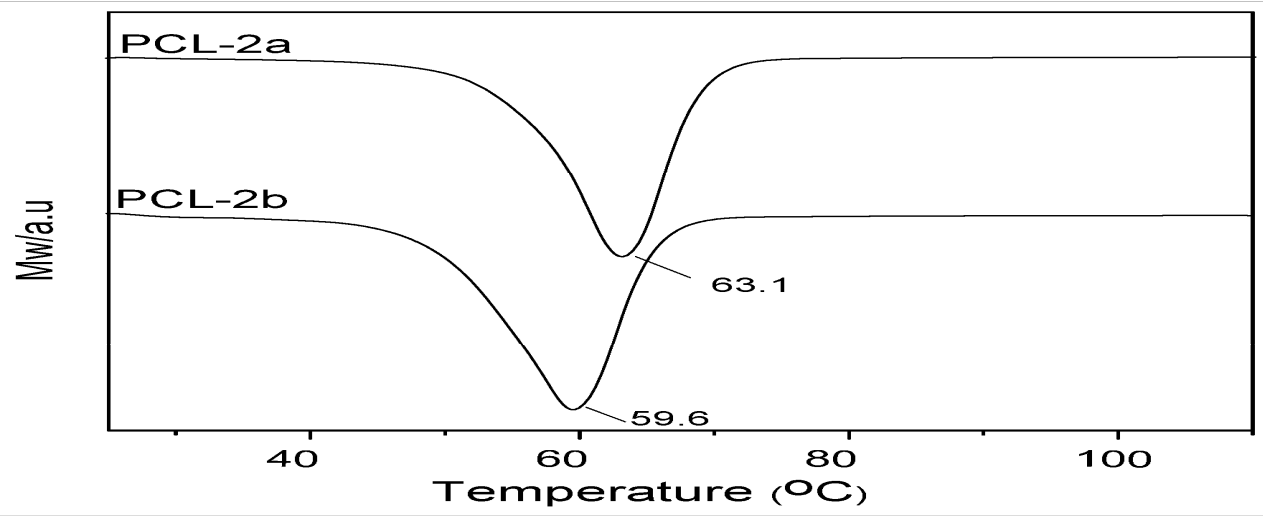

Fig.-5: DSC Thermograms of the Obtained PCL Using Catalyst 2a (PCL-2a), obtained PCL Using Catalyst 2b (PCL-2b).

The Tm of PCL obtained using catalyst $2 \mathrm{a}-2 \mathrm{~b}$ were observed between $59.6{ }^{\circ} \mathrm{C}$ and $63.1{ }^{\circ} \mathrm{C}$. The Tm of PCL is in the almost similar temperature range as previously have reported ${ }^{26-27}$ as shown in Table- 2. Meanwhile, the melting enthalpy $(\Delta \mathrm{Hm})$ of PCL obtained using catalyst $2 \mathrm{~b}$ shows higher $\Delta \mathrm{Hm}$ compared to those catalyzed by $2 \mathrm{a}$ as shown in Table- 2 .

The thermal properties of PCL are also characterized by using TGA which is shown in Fig.-6. TGA is an instrument that can measure the mass changes and the decomposition temperature (Td) of PCL. The TGA curve for all PCL obtained using catalyst $2 \mathrm{a}-2 \mathrm{~b}$ only shows one mass decrease curve, which is started from $272{ }^{\circ} \mathrm{C}$ to $438{ }^{\circ} \mathrm{C}$. Subsequently, the thermal decomposition of PCL occurs at the above temperatures $438{ }^{\circ} \mathrm{C}$ and no again change occurs (plateau). Based on the TGA curve, the Td of all PCLs obtained using catalyst $2 \mathrm{a}-2 \mathrm{~b}$ had the same results with the previous work, so the thermal stability of it is also almost the same. ${ }^{21,24}$

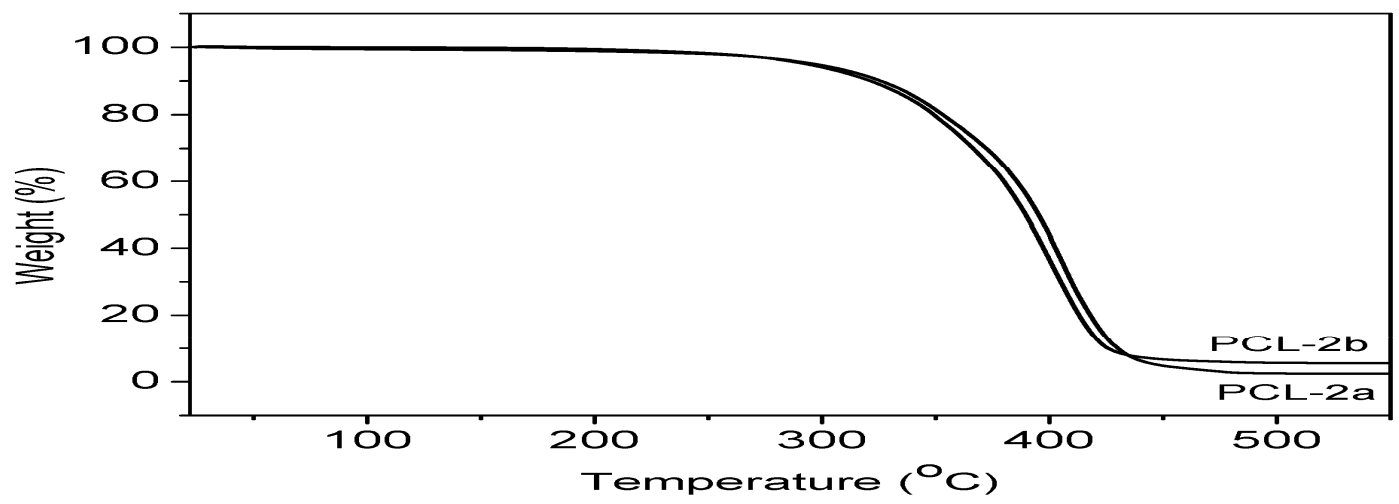

Fig.-6: TGA Thermogram of the PCL Obtained Using Catalyst 2a (PCL2a) and 2b (PCL2b). Table-2: Thermal Analysis of PCL Obtained Using Catalyst 2a - 2b

\begin{tabular}{c|c|c|c|c}
\hline Catal & $\mathrm{T} d\left({ }^{\circ} \mathrm{C}\right)$ & $\mathrm{T} m\left({ }^{\circ} \mathrm{C}\right)$ & Enthalpy $(\mathrm{J} / \mathrm{g})$ & Polymer Phase \\
\hline 2a & $274-438$ & 63.18 & 111.2 & White solid \\
\hline 2b & $295-435$ & 59.62 & 109.0 & White solid \\
\hline
\end{tabular}


After analyzing PCL by using FTIR, ${ }^{1} \mathrm{H}$ NMR, ${ }^{13} \mathrm{C}$ NMR, XRD, DSC, and TGA, it is shown that the PCL obtained in this research have the same result as the previous work. ${ }^{21-27}$ But the catalyst carried out in this work was $2 \mathrm{a}-2 \mathrm{~b}$ catalysts.

\section{Plausible Mechanism of ROP of $\varepsilon-\mathrm{CL}$}

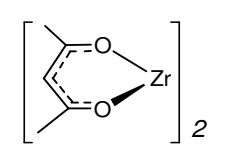

Zr-complex

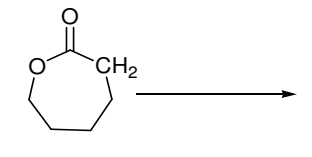

$\varepsilon-\mathrm{CL}$<smiles>CC12CCCC(CC1)OC(C)(OC1CCCCO1)O2</smiles>

complex 1

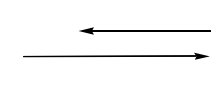

(n)

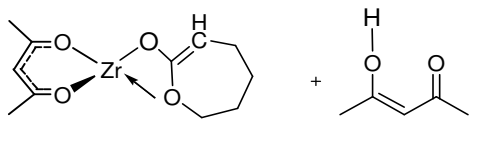

complex 2
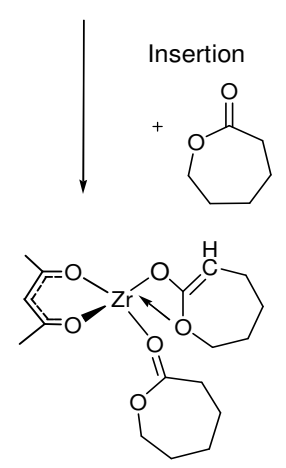

complex 3<smiles>OC(CCCCCOC1OC2COC1O2)OC1CCCCO1</smiles>
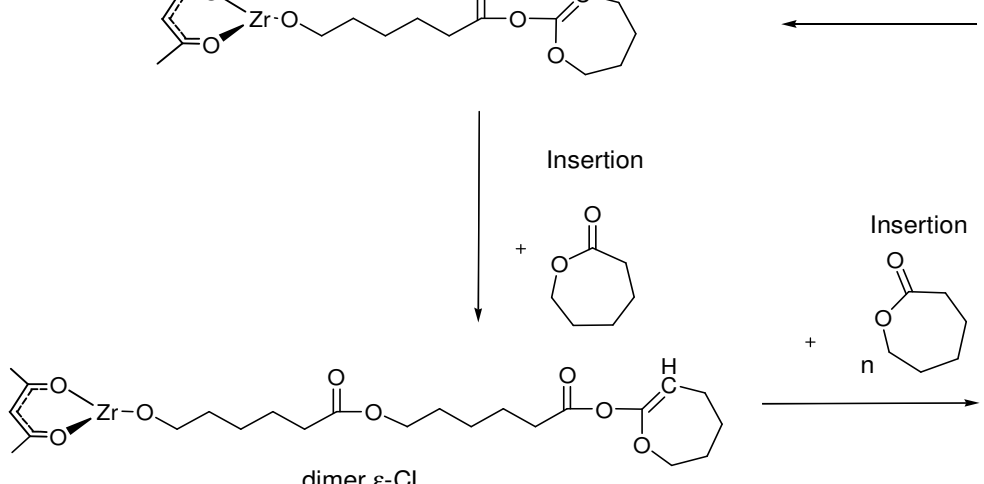

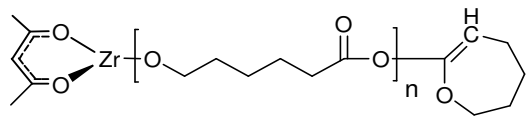

PCL

Scheme-3: The proposed mechanism of ROP of $\varepsilon$-CL using bis( $\beta$-diketonato)zirconium(IV) chloride catalyst

There are several reaction steps to obtain PCL using bis( $\beta$-diketonato)zirconium (IV) chloride catalyst, i.e. coordination, deprotonation, insertion, and the chain propagation step as shown in Scheme-3. ${ }^{11}$ The first step was the formation an unstable five-coordination compound (Complex 1) via coordination of carbonyl oxygen from $\varepsilon$-CL on the zirconium central atom. The second step was deprotonation of $\varepsilon$-CL followed by the proton transfer on the acac ligands causes ligand exchange reactions that produce a stable four-coordination compound (complex 2). At this step, Hacac ligand dissociation also occurred. The third step was the coordination of the second $\varepsilon$-CL molecule to the zirconium central atom via the carbonyl oxygen-free electron pair ( $\varepsilon$-CL) to form an intermediate five-coordination compound (complex 3$)$. As a result, an acyl oxygen-zirconium bond was formed. The fourth step was the chain propagation through the insertion of the $\varepsilon$-CL molecule that corresponding with the coordination mechanism (dimer $\varepsilon$-CL). The insertion process can be continued to form a longer PCL after the next $\varepsilon$-CL molecule was coordinated at the zirconium central atom. The optimized geometries of reactant and complex as shown in Fig.-7.

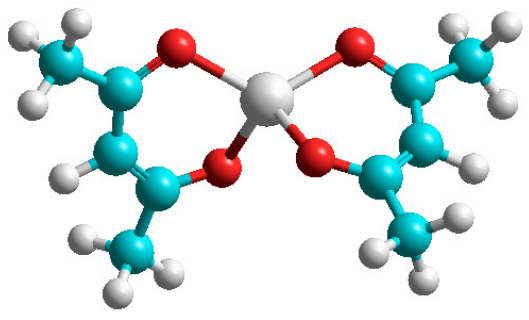

Zr-complex

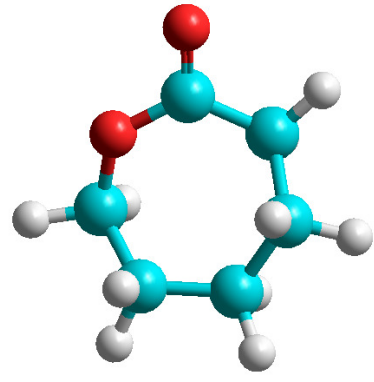

$\varepsilon-\mathrm{CL}$ 


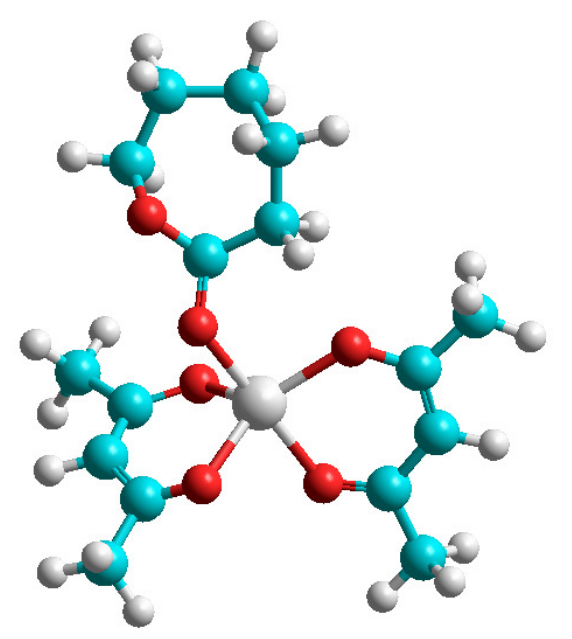

Complex 1

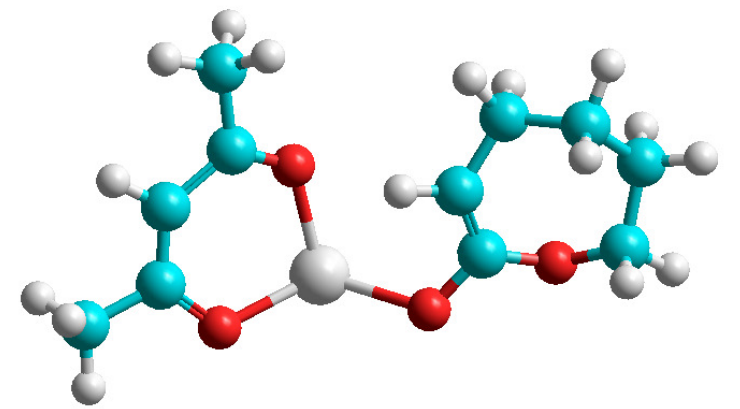

Complex 2

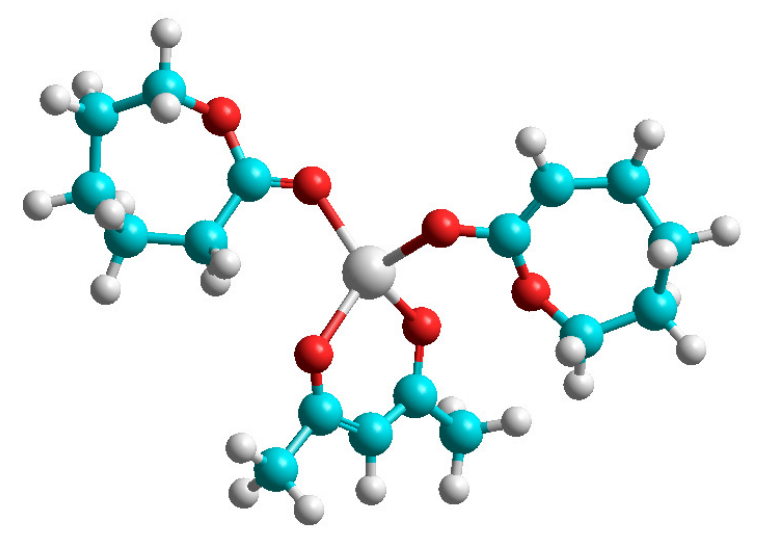

Complex 3

Fig.-7: Optimized Geometries of the Intermediates States During ROP of $\varepsilon$-CL using bis $(\beta$ diketonato)Zirconium (IV) Chloride Catalyst

\section{CONCLUSION}

PCL has been successfully obtained in this research by using catalyst $2 \mathrm{a}-2 \mathrm{~b}$ at $100{ }^{\circ} \mathrm{C}$ for $4 \mathrm{~h}$. PCL generated by using catalyst $2 \mathrm{~b}$ has a DP of 20 . Meanwhile, PCL generated by using $2 \mathrm{a}-2 \mathrm{~b}$ catalysts has the degree crystallinity (Xc) around 83\% (PCL-2a) and 80\% (PCL-2b) so it's a semicrystalline polymer. The high Xc of PCL generated by using $2 \mathrm{a}-2 \mathrm{~b}$ related to the high regularity of the PCL chain. Furthermore, PCL generated by using catalyst $2 \mathrm{a}-2 \mathrm{~b}$ has a melting temperature of around $59.6{ }^{\circ} \mathrm{C}$ and $63.7^{\circ} \mathrm{C}$ respectively. Whereas the thermal decomposition of PCL occurs starts from $272{ }^{\circ} \mathrm{C}$ to $438^{\circ} \mathrm{C}$. On the other hand, the reaction mechanism of PCL obtained using bis( $\beta$-diketonato)zirconium(IV) chloride catalyst occurs through four reaction steps, they are coordination, deprotonation, insertion, and chain propagation.

\section{ACKNOWLEDGMENT}

For the research, the authors express gratitude to the Dirjend Penguatan Riset dan Pengembangan, Republik Indonesia for financial support of this research via Hibah PDUPT 2018 (Nomor: 073/SP2H/LT/DRPM/2018), and 2019 (190/SP2H/LT/DRPM/2019). We also express gratitude to Universitas Negeri Medan for facility support of this research.

\section{REFERENCES}

1. B. Yamini, and R. Nanthini, Rasayan Journal of Chemistry, 11(1), 413(2018), DOI: 10.7324/RJC.2018.1112002.

2. B. Yamini, and R. Nanthini, Rasayan Journal of Chemistry, 11(2), 440(2018), DOI: 10.31788/RJC.2018.1121992. 
3. T.O. Siyanbola, A. F. Akinsola, O. R. Obanla, A. A. Adebisi1, A. A. Akinsiku, I. O. Olanrewaju, K. O. Ogunniran, O. S. Taiwo, K. O. Ajanaku, and O. A. Bamgboye, Rasayan Journal of Chemistry, 10(3), 1003(2017), DOI: 10.7324/RJC.2017.1031811.

4. M. Arcana, B. Tanajaya, B. Anwar, C. L. Radiman, and M. A. Sulfikar, Journal of Mathematical and Fundamental Sciences, 37A(2), 93(2005), DOI: 10.5614\%2Fitbj.sci.2005.37.2.1.

5. C. C. Eng, N. A. Ibrahim, N. Zainuddin, H. Ariffin, W. M. Z. W. Yunus, and Y. Y. Then, International Journal of Polymer Science, ID 715801, 1 (2014), DOI: 10.1155/2014/715801.

6. S. Gea, C.T. Reynolds, N. Roohpur, N. Soykeabkaew, B. Wirjosentono, E. Bilotti, and T. Peijs, Journal of Biobased Materials and Bioenergy, 4(4), 384 (2010), DOI:10.1166/jbmb.2010.1108.

7. M.Tarnacka, A. Dzienia, P. Maksym, A. Talik, A. Zięba, R. Bielas, K. Kaminski, M. Paluch, Macromolecules, 51(12), 4588 (2018), DOI: 10.1021/acs.macromol.8b00409.

8. Z. Grobelny1, S. Golba, J. J.-Suliga, Polymer Bulletin, 76, 3501 (2019), DOI: 10.1007/s00289-0182554-0.

9. R. M. Slattery, A. E. Stahl, K. R. Brereton, A. L. Rheingold, D. B. Green, J. M. Fritsch, Journal of Polymer Science, Part A: Polymer Chemistry, 57, 48 (2019), DOI: 10.1002/pola.29280.

10. N. Wanna, T. Kraithong, T. Khamnaen, P. Phiriyawirut, S. Charoenchaidet, J. Tantirungrotechai, Catalysis Communications, 45, 118 (2014), DOI: 10.1016/j.catcom.2013.11.009.

11. P. Dobrzynski, Polymer, 48, 2263 (2007), DOI:10.1016/j.polymer.2007.02.005.

12. J. M. Campos, M. R. Ribeiro, M. F. Ribeiro, A. Deffieux, and F. Peruch, European Polymer Journal, 49, 4025 (2013), DOI: 10.1016/j.eurpolymj.2013.09.008.

13. X. Liu, C. Jian, D. Yu, J. Zhang, N. Tang, C. Wang, J. Wu, Inorganic Chemistry Communications, 36, 206(2013), DOI: 10.1016/j.inoche.2013.09.015.

14. H.-L.Chen, H.-J.Chuang, B.-H.Huang, and C.-C. Lin, Inorganic Chemistry Communications, 35 , 247(2013), DOI: 10.1016/j.inoche.2013.06.048.

15. I. M.Arcana, M. Hasan, S.D. Anggraini, A.A. Febrianti, and A. Ardana, ITB Journal of Science, 41A(2), 78(2009), DOI: 10.5614\%2Fitbj.sci.2009.41.2.2.

16. Y. Permana, S. Shimazu, N. Ichikuni, T. Uematsu, Catalysis Communications, 6, 426(2005), DOI:10.1016/j.catcom.2005.03.012.

17. Y. Permana, N. Ichikuni, S. Shimazu, ITB Journal of Science, 44, 263(2012), DOI: 10.5614/itbj.sci.2012.44.3.6.

18. M. Yusuf and D.E. Sitepu, AIP Conference Proceeding, 1803, 020055-1(2017) DOI: $10.1063 / 1.4973182$.

19. M. Yusuf, D. Roza and A.K. Nasution, AIP Conference Proceeding, 1904, 020012-1 (2017), DOI: 10.1063/1.5011869.

20. M. Yusuf, Dahniar, D. Roza and M. Damanik, Asian Journal of Chemistry, 31(5), 982 (2019), DOI: 10.14233/ajchem.2019.21662.

21. A. Elzubair , C. N. Elias, J. C. M. Suarez, H. P. Lopes, M. V. B. Vieira, Journal of Dentistry, 34, 784 (2006), DOI: 10.1016/j.jdent.2006.03.002.

22. T. K. Sen, A. Mukherjee, A. Modak, S. K. Mandal and D. Koley, Dalton Trans, 42, 1893(2013), DOI: $10.1039 / \mathrm{c} 2 \mathrm{dt} 32152 \mathrm{a}$.

23. T. Öztürk and E. Meyvac1, Journal of Macromolecular Science, Part A,_Pure and Applied Chemistry, 54, 9(2017), DOI: 10.1080/10601325.2017.1309251.

24. J. Han, L. Zhu, S. Zheng, European Polymer Journal, 48, 730(2012), DOI: 10.1016/j.eurpolymj.2012.01.020.

25. M. Ravi, S. H. Song, K. M. Gu, J. N. Tang and Z. Y. Zhang, Ionics, 21(8), 2171(2015), DOI: 10.1007/s11581-015-1384-4.

26. Y. Liu, W. S. Dong, J.Y. Liu, and Y. S. Li, Dalton Trans, 43, 2244(2014), DOI: $10.1039 / \mathrm{c} 3 \mathrm{dt} 52712 \mathrm{c}$.

27. Y. Wang, M. A. Rodriguez-Perez, R. L. Reis, J. F. Mano, Macromolecular Materials and Engineering, 290, 792 (2005), DOI: 10.1002/mame.200500003.

[RJC-5463/2019] 